\title{
CrystEngComm
}

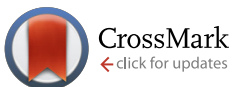

Cite this: CrystEngComm, 2016, 18, 4971

\section{Conformational changes in $\mathrm{C}_{\text {methyl-resorcinarene }}$ pyridine $\mathbf{N}$-oxide inclusion complexes in the solid state $\dagger$}

\author{
Rakesh Puttreddy, ${ }^{a}$ Ngong Kodiah Beyeh ${ }^{\text {ab }}$ and Kari Rissanen*a
}

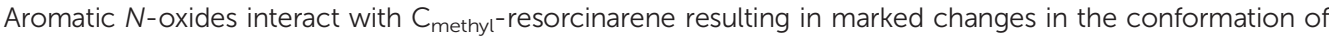
the host resorcinarene. In the solid state, 2- and 3-methylpyridine $N$-oxides form pseudo-capsular 2:2

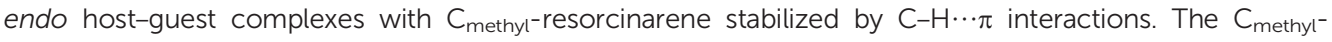
resorcinarene.2-methylpyridine $\mathrm{N}$-oxide complex has a $\mathrm{C}_{4 \mathrm{v}}$ crown conformation, while the $\mathrm{C}_{\text {methyl- }}{ }^{-}$ resorcinarene.3-methylpyridine $\mathrm{N}$-oxide complex has a slightly open $\mathrm{C}_{2 v}$ boat conformation. On the contrary, other para-substituted and benzo-fused pyridine $\mathrm{N}$-oxides form only exo complexes with

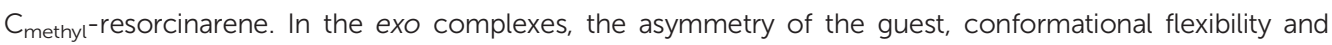

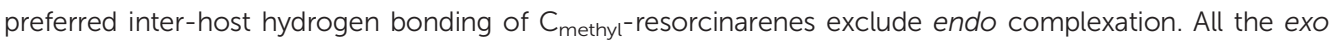
complexes form robust 1-D hydrogen bonded chains between the host hydroxyl groups assisted by the guest $\mathrm{N}-\mathrm{O}$ groups, resulting in a $\mathrm{C}_{2 \mathrm{v}}$ boat conformation.
\end{abstract}

Received 29th January 2016,
Accepted 26th February 2016

DOI: $10.1039 /$ c6ce00240d

www.rsc.org/crystengcomm

Other unusual conformations such as the rarely observed $r c c t$-diamond $\mathrm{C}_{\text {methyl }}$-resorcinarene, ${ }^{3}$ the $r c c t$-boat $\mathrm{C}_{\text {methyl }}{ }^{2-}$ nitroresorcinarene $e^{4}$ and the $r c c t$-crown $\mathrm{C}_{4 t}$-pyrogallarene $(4 t=$ tert-butyl) ${ }^{5}$ have been reported. In the $C_{4 \mathrm{v}}$ conformation, intramolecular circular hydrogen bonds (HB) between adjacent phenolic hydroxyl groups preserve the crown structure. ${ }^{5}$ In this conformation, the $\pi$-rich cavity is suitable for inclusion of spherical and planar guests such as ammonium and phosphonium cations, the main complexation force being the cation $\cdots \pi$ interactions. ${ }^{6}$ With resorcinarenes, these cationic guests play a key role in numerous solid-state architectures such as open inclusion complexes, ${ }^{7}$ dimers, ${ }^{8}$ hexamers, ${ }^{9}$ and tubular assemblies. ${ }^{10}$ Though inclusion complexes of resorcinarenes with cationic compounds are prevalent, there are several reports of complexes with neutral N-heteroaromatic five- and sixmembered planar guests as well. ${ }^{11} \mathrm{~N}$-Aromatic compounds such as 2,2'- and 4,4'-bipyridines, due to their size and strong hydrogen bond acceptor properties, have been particularly effective in inducing conformational changes in resorcinarene complexes. ${ }^{12}$ A Cambridge Structural Database (CSD) ${ }^{13}$ search using $\mathrm{C}_{\text {methyl }}$-resorcinarene 1 as the host revealed 34 crystal structures with $4,4^{\prime}$-bipyridine as the guest molecule. ${ }^{14,12 a-c}$

Aromatic $N$-oxides are well-known synthetic intermediates for functionalization of the pyridine ring in organic synthesis, ${ }^{15}$ and as ligands in supramolecular chemistry. ${ }^{16}$ The oxygen in the $\mathrm{N}$-oxide group can exhibit hyper-dentate coordination behaviour with metal cations, resulting in interesting supramolecular architectures. ${ }^{16}$ Most recently, pyridine $N$-oxides (PyNOs) have been shown to be excellent halogen bond acceptors and thus form very strong halogen bonds. ${ }^{17}$ The 
$\mathrm{N}$-oxide, viz. ${ }^{+} \mathrm{N}-\mathrm{O}^{-}$, group makes the aromatic ring electron deficient but the electron deficiency can be modulated by the substituents on the aromatic ring, and due to this, aromatic $\mathrm{N}$-oxides can act as guest molecules with calixarenes and cavitands. ${ }^{18}$ Recently, we have reported dimeric pseudocapsular assemblies with aromatic $N$-oxides using $\mathrm{C}_{\text {ethyl }}$ 2- $^{-}$ methylresorcinarene as the host. ${ }^{19}$ The $\mathrm{C}-\mathrm{H} \cdots \pi$ and $\pi \cdots \pi$ interactions $^{20}$ have proven to be the governing factors in the recognition of electron-deficient $N$-oxides by $\pi$-rich host systems.

In addition, halogen bond breaking using $\mathrm{C}_{\text {ethyl-2- }}$ methylresorcinarene in halo-substituted pyridine $\mathrm{N}$-oxide systems was an unexpected result of the conformational change in the host. ${ }^{21}$ While our previous work has focused on $\mathrm{C}_{\text {ethyl }}{ }^{-}$ 2-methylresorcinarene, ${ }^{19,21}$ there exists one study with 4,4'bipyridine $N, N^{\prime}$-dioxide and $\mathrm{C}_{\text {methyl-resorcinarene as the }}$ host. $^{22}$ In this work, we report solid-state complexes with

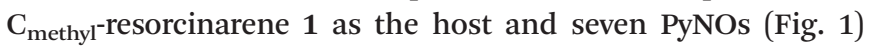
as the guests, and the conformational behaviour of the host upon complexation.

\section{Results and discussion}

\section{X-ray crystallography}

Single crystals of the complexes were obtained from slow evaporation of the methanolic solution of a 1:1 mixture of the host and guest molecules. Attempts to crystallize PyNO,

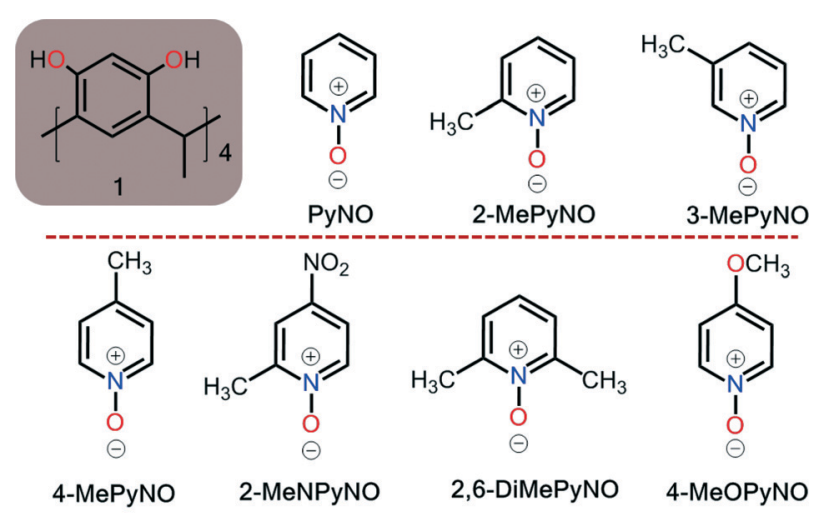

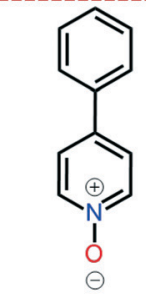

4-PhPyNO<smiles>[O-][n+]1cccc2ccccc21</smiles>

QNO

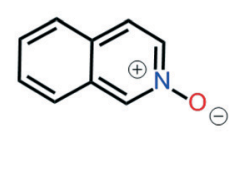

IsQNO
Fig. 1 The chemical structures of $C_{\text {methyl-resorcinarene (1), pyridine }}$ $\mathrm{N}$-oxide (PyNO), 2-methylpyridine $\mathrm{N}$-oxide (2-MePyNO), 3-methylpyridine $\mathrm{N}$-oxide (3-MePyNO), 4-methylpyridine $\mathrm{N}$-oxide (4-MePyNO), 2-methyl-4-nitropyridine $N$-oxide (2-MeNPyNO), 2,6-dimethylpyridine $\mathrm{N}$-oxide (2,6-DiMePyNO), 4-methoxypyridine $\mathrm{N}$-oxide (4-MeOPyNO), 4-phenylpyridine $N$-oxide (4-PhPyNO), quinoline $N$-oxide (QNO), and isoquinoline $\mathrm{N}$-oxide (ISQNO).
2,6-DiMePyNO and QNO with 1 were unsuccessful. In the endo complexes, the $\mathrm{N}$-oxide oxygen atoms point away from the cavity (Fig. 2). Complexes of 2-MePyNO and 3-MePyNO with host 1 resulted in mixed endo/exo complexes, 2MePyNO-1 and 3-MePyNO-1 (Fig. 2), which are remarkably similar to our previous results with $\mathrm{C}_{\text {ethyl }}{ }^{2-}$ methylresorcinarene. ${ }^{21}$ Complex 2-MePyNO-1 [formally 1:(2MePyNO $\left.)_{\text {endo }}: 3(2-\mathrm{MePyNO})_{\text {exo }}\right]$ can be described as a discrete dimeric pseudo-capsular 2:2 complex which is then hydrogen bonded to six exo-cavity 2-MePyNO molecules, as shown in Fig. 2b. In complex 2-MePyNO-1, host 1 retains the crown conformation (centroid-to-centroid distances being nearly equal, ca. 6.8/7.0 Å, Fig. 3), encapsulating one 2-MePyNO molecule. The guest, 2-MePyNO, resides $3.2 \AA$ from the centroid of the lower rim carbon atoms (calculated from the PyNO benzene ring carbon deepest in the cavity). The hydrogen atoms para to the $\mathrm{N}-\mathrm{O}$ and $-\mathrm{CH}_{3}$ groups of 2-MePyNO manifest $\mathrm{C}-\mathrm{H} \cdots \pi$ interactions with the aromatic rings of host 1 with distances ranging between $2.7 \AA$ and $3.1 \AA$ (Fig. 3a). Complex 3-MePyNO-1 [formally 1:(3-MePyNO) endo $_{\text {: (3- }}$ MePyNO) $)_{\text {exo }}$ forms a similar dimeric pseudo-capsular 2:2 complex to 2-MePyNO (Fig. 2c). These dimers are hydrogenbonded to each other by bridging exo 3-MePyNO molecules as shown in Fig. 2d. In complex 3-MePyNO-1, the cavity of host 1 is elongated so that the centroid-to-centroid distances

(a)
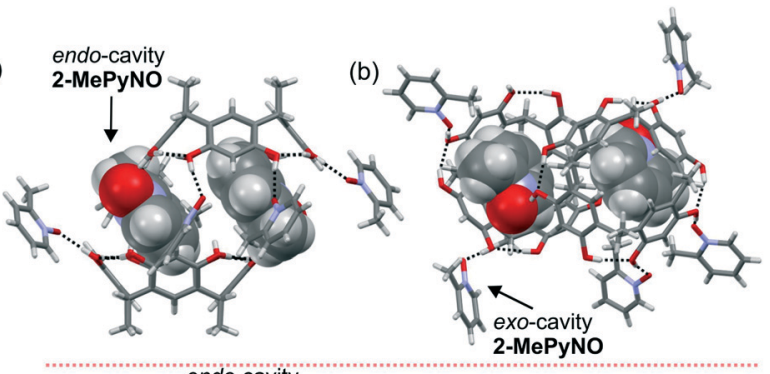

(c)

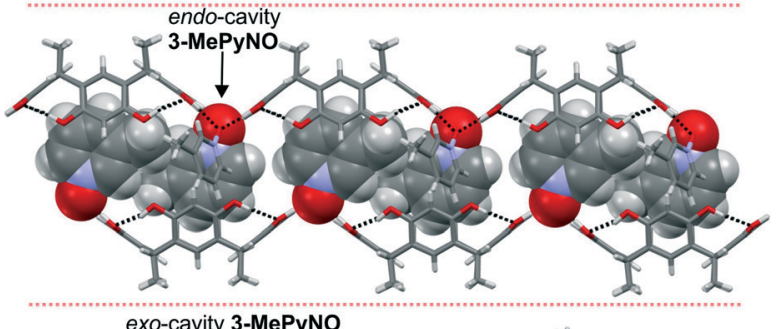

(d)

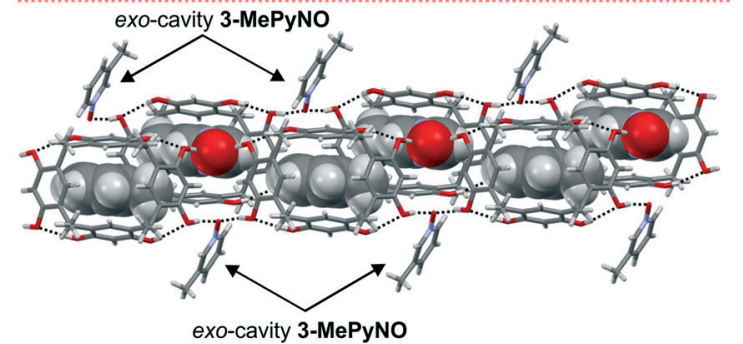

Fig. 2 (a) Side view of the discrete dimeric structure of 2-MePyNO.1, and (b) top view showing exo-cavity HB monodentate decorated 2MePyNO with host 1. (c) Section of the 1-D polymeric crystal packing in 3-MePyNO.1 showing endo 3-MePyNO as a bidentate HB acceptor, and the respective (d) side view showing the exo-cavity $\mathrm{HB}$ bidentate 3-MePyNO molecules. 

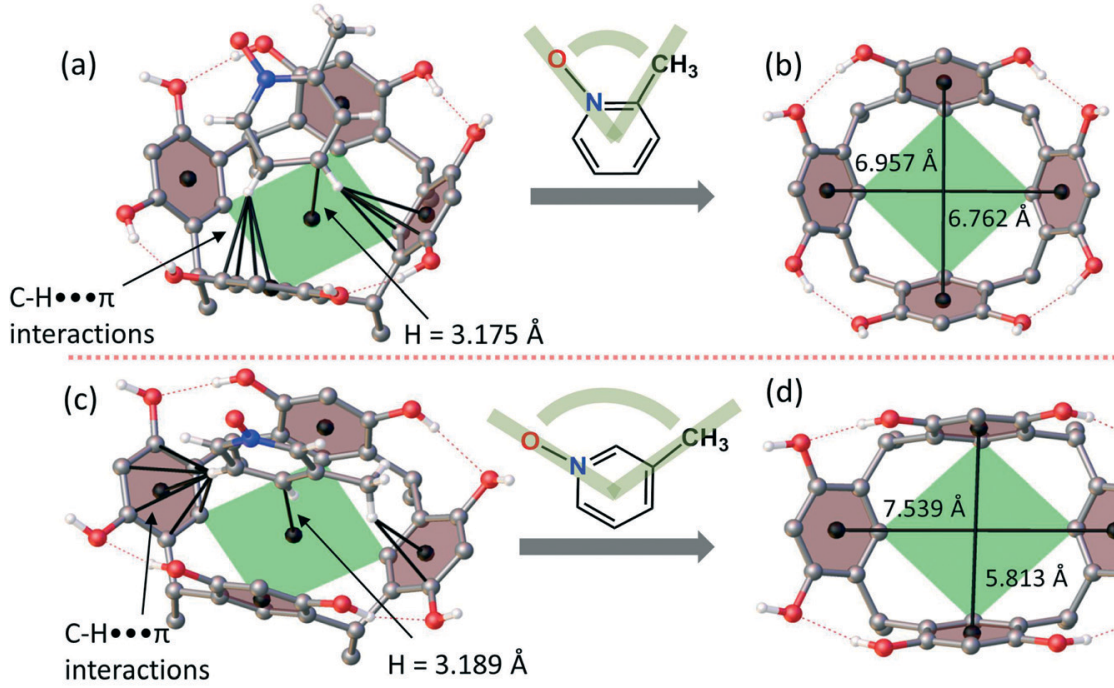

(d)

(e)

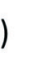

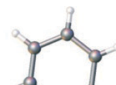
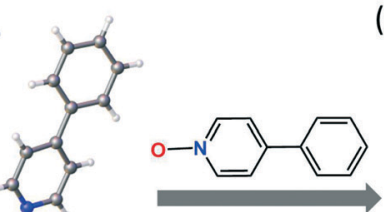

(f)

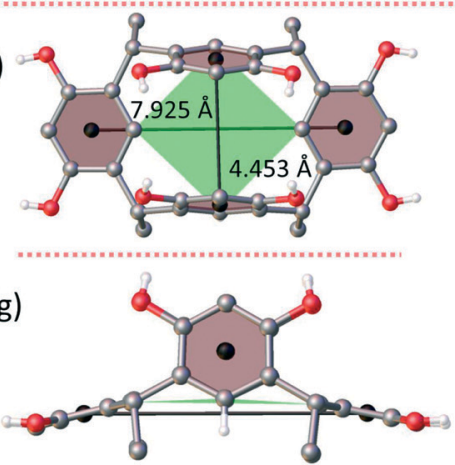

Fig. 3 (a) $\mathrm{C}-\mathrm{H} \cdots \pi$ interactions in 2-MePyNO.1. (b) The cavity of host 1 in 2-MePyNO.1 highlighting the flexibility. (c) C-H $\cdots \pi$ interactions in $3-$ MePyNO.1. (d) The cavity of host 1 in 3-MePyNO.1 highlighting the flexibility. (e) Complex 4-PhPyNO.1 displaying bidentate bridging 4-PhPyNO molecules through $(\mathrm{N}-\mathrm{O}) \cdots(\mathrm{H}-\mathrm{O})$ interactions. (f) Top view of the $C_{2 v}$ boat conformer in complex 4-PhPyNO.1. (g) Side view of the $C_{2 v}$ boat conformer in complex 4-PhPyNO.1. Black broken lines in Fig. 3e represent $(\mathrm{N}-\mathrm{O}) \cdots(\mathrm{H}-\mathrm{O})$ interactions.

are 5.8 and $7.5 \AA$ to accommodate the slightly bigger 3MePyNO molecule, as shown in Fig. 3d. The endo guest in 3MePyNO.1 is situated $3.2 \AA$ from the centroid of the lower rim carbon atoms, exactly the same distance as that in 2MePyNO-1 and previously studied 3-MePyNO $\mathrm{C}_{\text {ethyl }}{ }^{2-}$ methylresorcinarene. ${ }^{21}$ In 3-MePyNO·1, the guest is situated near the center of the cavity between the benzene rings with no apparent aromatic $\pi \cdots \pi$ interaction, but manifesting a weak methyl $\mathrm{C}-\mathrm{H} \cdots \mathrm{O}$ hydrogen bond to the host $\mathrm{O}-\mathrm{H}$ group (C-H $\cdots \mathrm{O}$ distance of $2.51 \AA$ ) and $\mathrm{C}-\mathrm{H} \cdots \pi$ interactions from the hydrogen atoms meta to the $\mathrm{N}-\mathrm{O}$ group (Fig. 3c). These $\mathrm{C}-\mathrm{H} \cdots \pi$ distances range from $2.8 \AA$ to $2.9 \AA$. The increased conformational flexibility of host 1 and the larger guest size in the endo complexation via the $\mathrm{C}-\mathrm{H} \cdots \pi$ interactions between the host and the guest distort the parent $C_{4 \mathrm{v}}$ crown conformation to a nearly ideal $C_{2 \mathrm{v}}$ boat conformation (Fig. 3d). With our previous work on resorcinarene endo PyNO complexes, ${ }^{21}$ the PyNOs located deep in the cavity, viz. $<2.9 \AA$ from the centroid of the lower rim carbon atoms, usually show short $\mathrm{C}-\mathrm{H} \cdots \pi$ (centroid) contacts. However in 3MePyNO-1, where the 3-MePyNO guest is situated higher in the cavity $(3.2 \AA)$, the shortest $\mathrm{C}-\mathrm{H} \cdots \pi$ (centroid) distance of ca. $2.5 \AA$ was observed. Comparing the host-guest chemistry of 2-MePyNO-1 and 3-MePyNO-1 with that of $\mathrm{C}_{\text {ethyl }}$ 2methylresorcinarene, ${ }^{21}$ both host systems show a similar encapsulation profile to 2-MePyNO and 3-MePyNO. In general, the formation of endo complexes with host $\mathbf{1}$ is considerably more difficult than that with conformationally more rigid host molecules due to the stronger influence of the intermolecular hydrogen bonding between the hosts, which can lead to the conformational change and subsequent formation of host-to-host 1-D, 2-D or 3-D networks.

The conformational flexibility of resorcinarenes is due to their lower rim $\mathrm{R}$ chains. The methyl chain is smaller, thus allowing more different conformations for the resorcinarene skeleton. The ethyl chain is sterically more bulky and thus results in conformationally less flexible resorcinarenes. ${ }^{2,5}$ Sterically suitable PyNOs like 2-MePyNO and 3-MePyNO which do form endo complexes with conformationally flexible host systems are also proven to form endo complexes with more rigid systems; this we have recently shown with $\mathrm{C}_{\text {ethyl }}{ }^{2-}$ methylresorcinarene. $^{21}$ The question arises if the larger PyNOs $^{21}$ would also behave similarly to the more flexible host 1. As such, larger PyNOs were utilized to probe their behaviour. 
Complexes 4-MePyNO-1 [formally 1:2(4-MePyNO) $)_{\text {exo }}$ : $\mathrm{CH}_{3} \mathrm{OH}$ ], 4-MeOPyNO-1 [formally 1:2(4-MeOPyNO) $)_{\text {exo }}$ ], 2MeNPyNO-1 [formally $1: 2(2-\mathrm{MeNPyNO})_{\text {exo }}: 4 \mathrm{CH}_{3} \mathrm{OH}: \mathrm{H}_{2} \mathrm{O}$ ], 4PhPyNO-1 [formally 1:2(4-PhPyNO) exo], and IsQNO-1 [formally $\left.1: 2(\text { IsQNO) })_{\text {exo }}: 4 \mathrm{CH}_{3} \mathrm{OH}: 4 \mathrm{H}_{2} \mathrm{O}\right]$ manifest only exo complexes with a prominent feature being the formation of 1-D tubular hydrogen-bonded chains with a $C_{2 \mathrm{v}}$ boat conformation of the host (Fig. 3f and g). The asymmetric structure and larger size of these PyNOs prevent the formation of endo complexes and the ease of intermolecular hydrogen bond formation leads to the formation of host-to-host 1-D tubular chains in all complexes, as shown in Fig. 4. During crystallization, the host interactions with themselves, the guest and the solvent molecules (methanol and water) change the conformation from the $C_{4 \mathrm{v}}$ crown to $C_{2 \mathrm{v}}$ boat and provide possibilities for better intermolecular hydrogen bonding between the hydroxyl groups of the hosts. Two types of 1-D chains were observed, only PyNOs (type 1) and a combination of PyNOs and solvent molecules (type 2). The type 1 situation appears in complexes 4-MeOPyNO-1 and 4-PhPyNO-1, while type 2 is observed in complexes 2-MeNPyNO-1 and IsQNO-1 (Fig. 5 and ESI, $\dagger$ Fig. S6).

In complex 4-MePyNO-1, the 4-MePyNO molecules bridge the hosts via the $\mathrm{N}$-oxide oxygen atom $(\mathrm{O}-\mathrm{H})_{\text {host }} \cdots(\mathrm{O}-\mathrm{N}) \cdots(\mathrm{O}-\mathrm{H})_{\text {host }}$ with distances of 2.60 and $2.67 \AA$, generating a zigzag 1-D tubular chain (Fig. 5a). A closer look at the 3-D crystal packing reveals that the 4-MePyNO molecules of the 1-D polymeric chain are additionally stabilised by $\pi \cdots \pi$ interactions at centroid-to-centroid distances of $c a$. $3.9 \AA$ (ESI, $\dagger$ Fig. S1b). Both 4-MeOPyNO-1 and 4-PhPyNO-1 manifest a regular 1-D chain joined by the bidentate $N$-oxide oxygen atom with $(\mathrm{O}-\mathrm{H})_{\text {host }} \cdots(\mathrm{O}-\mathrm{N}) \cdots(\mathrm{O}-\mathrm{H})_{\text {host }}$ distances of $2.64 \AA$ (4-MeOPyNO-1), and $c a$. 2.66-2.72 $\AA$ (4-PhPyNO-1) as shown in Fig. 5b and c.

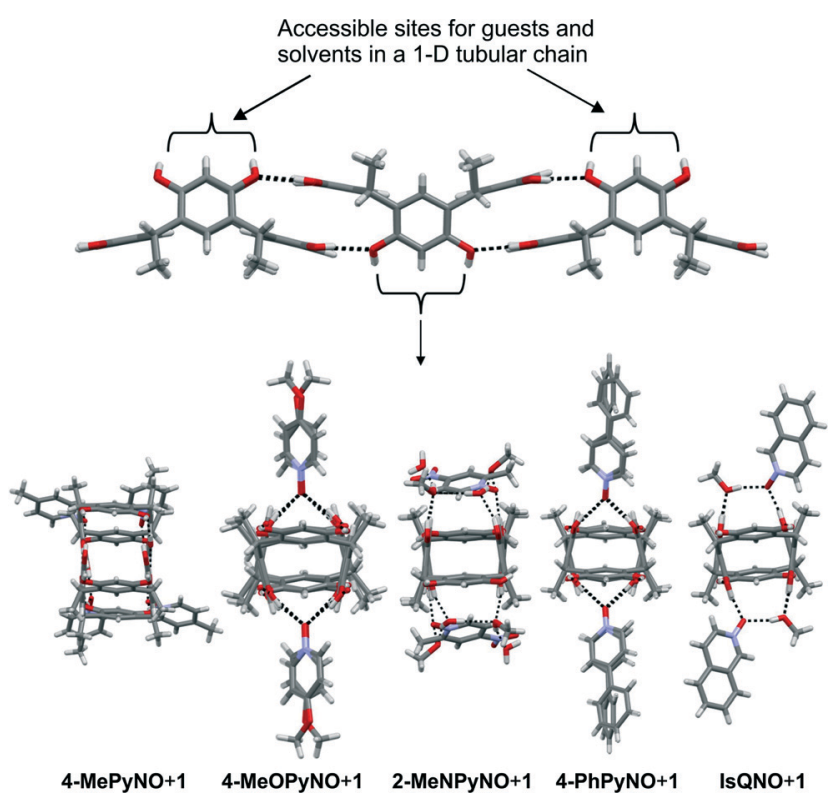

Fig. 4 Repeating units of the crystal packing viewed along the 1-D chains of complexes in 4-MePyNO.1, 4-MeOPyNO.1, 2-MeNPyNO.1, 4-PhPyNO.1, and IsQNO.1 (left to right).
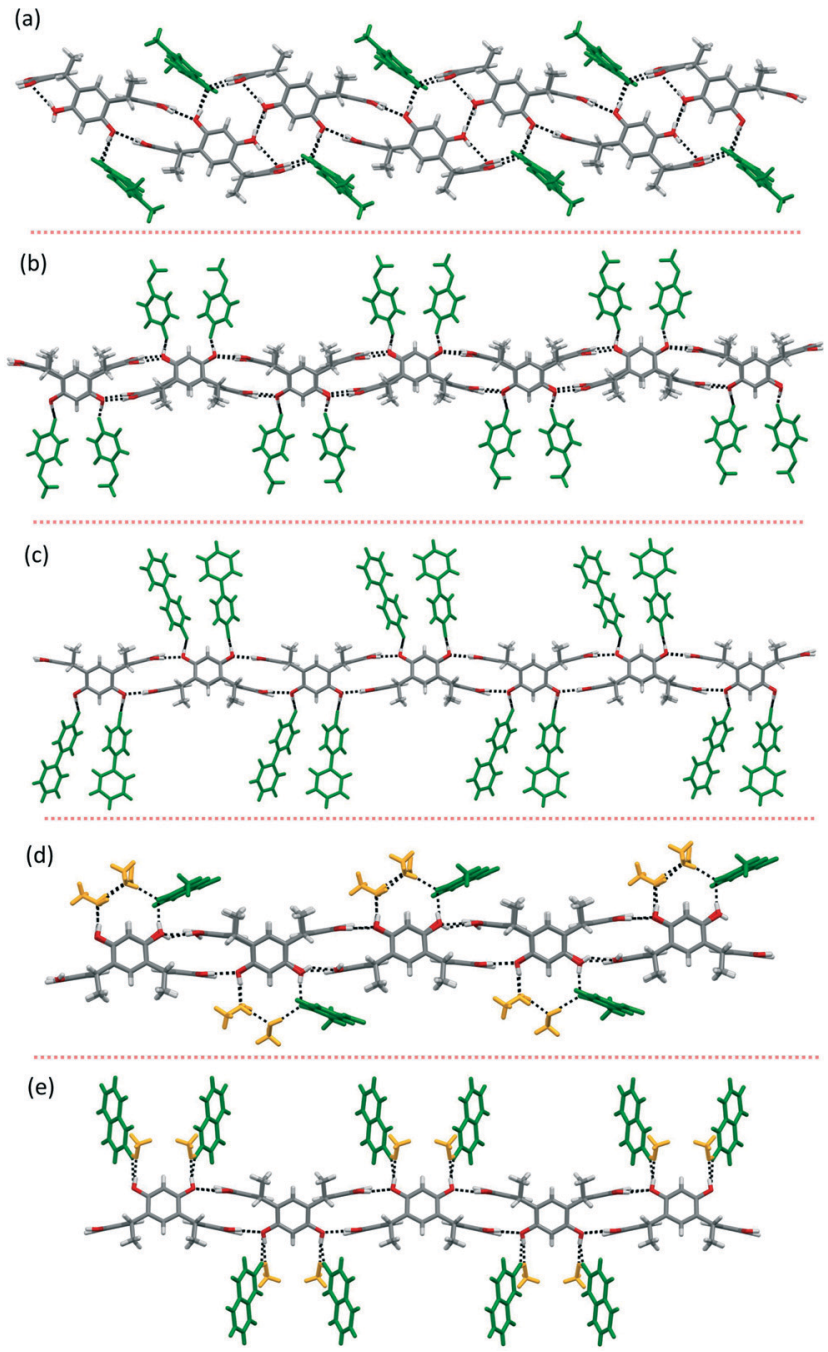

Fig. 5 Side view of the 1-D HB chains of host 1. (a) 4-MePyNO.1, (b) 4-MeOPyNO.1, (c) 4-PhPyNO.1, (d) 2-MeNPyNO.1 and (e) IsQNO.1. The PyNO molecules are shown in green. The solvent molecules are shown in orange in figures (d) and (e).

Further analysis of the crystal packing shows that the 1-D chains in 4-MeOPyNO.1 and 4-PhPyNO.1 interdigitate to form 2-D supramolecular sheets (see the ESI, $\dagger$ Fig. S2). These interdigitated 1-D chains are stabilized by $\mathrm{C}-\mathrm{H} \cdots \pi$ and $\pi \cdots \pi$ interactions. During interdigitation, the aromatic rings of host $\mathbf{1}$, and the hydrogen atoms of the methoxy group in 4MeOPyNO, and the para hydrogen atoms of 4-PhPyNO have short $\mathrm{C}-\mathrm{H} \cdots \pi$ contacts with distances of $c a .2 .8 \AA$ and $2.7 \AA$, respectively (see the ESI, $\dagger$ Fig. S2 and S3).

The host molecules in complex 2-MeNPyNO-1 also form a 1-D hydrogen bonded chain as shown in Fig. 5d. However, the hydrogen bonding via the hydroxyl groups of the host and the crystal packing differ due to interactions with solvent molecules and a second 2-MeNPyNO molecule in the asymmetric unit. Two methanol molecules, a water molecule and a 2-MeNPyNO molecule hydrogen bond to three host hydroxyl groups of the 1-D tubular chain in a continuous fashion $(\mathrm{O}-\mathrm{H})_{\text {host }} \cdots(\mathrm{O}-\mathrm{H})_{\mathrm{CH}_{3} \mathrm{OH}} \cdots(\mathrm{O}-\mathrm{H})_{\mathrm{H}_{2} \mathrm{O}} \cdots(\mathrm{O}-\mathrm{H})_{\mathrm{CH}_{3} \mathrm{OH}} \cdots(\mathrm{O}-\mathrm{N})_{\text {PyNO }}$ 
(see the ESI, $\uparrow$ Fig. S4a). Also, the second 2-MeNPyNO molecule hydrogen bonds to water and resides close to the host aromatic ring at centroid-to-centroid distances of $c a$. 3.7 A. The crystal packing of 2-MeNPyNO-1 shows that the 1-D chains are connected by two methanol molecules to give a 2-D sheet motif (see the ESI, $\dagger$ Fig. S4c).

The mode of action of the host 1 hydroxyl groups in the 1-D polymeric chain of complex IsQNO-1 (Fig. 5e) is different from other complexes. The host hydroxyl groups are connected by methanol and IsQNO molecules through hydrogen bonds, $(\mathrm{O}-\mathrm{H})_{\text {host }} \cdots(\mathrm{O}-\mathrm{H})_{\mathrm{CH}_{3} \mathrm{OH}} \cdots(\mathrm{O}-\mathrm{N})_{\text {IsQNO }} \cdots(\mathrm{O}-\mathrm{H})_{\text {host }}$ with distances of ca. 2.61, 2.64 and $2.63 \AA$, respectively. Once again, the 1-D chains interdigitate by extensive $\mathrm{C}-\mathrm{H} \cdots \pi$ and $\pi \cdots \pi$ interactions between IsQNO molecules to give a 2-D sheet (see the ESI, $\dagger$ Fig. S5) motif. During interdigitation, the aromatic rings of IsQNO molecules have centroid-to-centroid distances of $c a$. $3.9 \AA$, and $\mathrm{C}-\mathrm{H} \cdots \pi$ contacts with the host aromatic rings at distances of $c a .2 .8 \AA$.

\section{Solution studies}

Solution studies between host 1 and PyNO, 2-MePyNO, 3MePyNO, 4-MePyNO, 2-MeNPyNO, 2,6-DiMePyNO, 4MeOPyNO, 4-PhPyNO, QNO and IsQNO as guests were conducted via ${ }^{1} \mathrm{H}$ NMR experiments in $\mathrm{CD}_{3} \mathrm{OD}$ at $293 \mathrm{~K}$. In these experiments, the host and guests were mixed in a 1:1 (6.6 $\mathrm{mM}$ on both molecules) ratio in $\mathrm{CD}_{3} \mathrm{OD}$; the ${ }^{1} \mathrm{H} \mathrm{NMR}$ spectra were measured and the results were compared with the free host (6.6 $\mathrm{mM})$ and free guests $(6.6 \mathrm{mM})$.

Complexation-induced shielding of the guest proton resonances was observed in all cases except with 4-PhPyNO. The shielding effects of the aromatic rings of the bowl-shaped host cavity upon addition of the guest are responsible for this upfield shift and indicate that guest exchange is fast on the NMR time scale. Taking the 1:1 mixture between 1 and 3MePyNO as an example (Fig. 6, I), the aromatic protons (g, f) are the most shielded (0.16 ppm and $0.17 \mathrm{ppm})$. These shift changes confirm the orientation of the guest deep in the host cavity, supporting the X-ray crystal structure (Fig. 3). Analysis of the 1:1 mixture between 1 and QNO (Fig. 6, II) reveals the aromatic protons (f, g) to be the most shielded (0.14-0.15 ppm), once again suggesting the localization of QNO within the host cavity. The analyses of the ${ }^{1} \mathrm{H}$ NMR results between the host and the other guests (PyNO, 2-MePyNO, 4-MePyNO, 2-MeNPyNO, 2,6-DiMePyNO, 4-MeOPyNO, and IsQNO) also indicate the localization of the guest in the host cavity (Fig. S7-S16†). No shift changes were observed with 4-PhPyNO, implying that in solution no host-guest complex is formed (Fig. S14 †).

Variable temperature (233-333 K) ${ }^{1} \mathrm{H}$ NMR experiments were done to probe the conformational changes of host 1 in the presence of the different guests (Fig. S17-S18†). No obvious changes in the host 1 signals were observed, implying that the conformational changes observed in the solid state with the $\mathrm{N}$-oxide guests are caused by multiple intermolecular interactions existing only in the solid state.
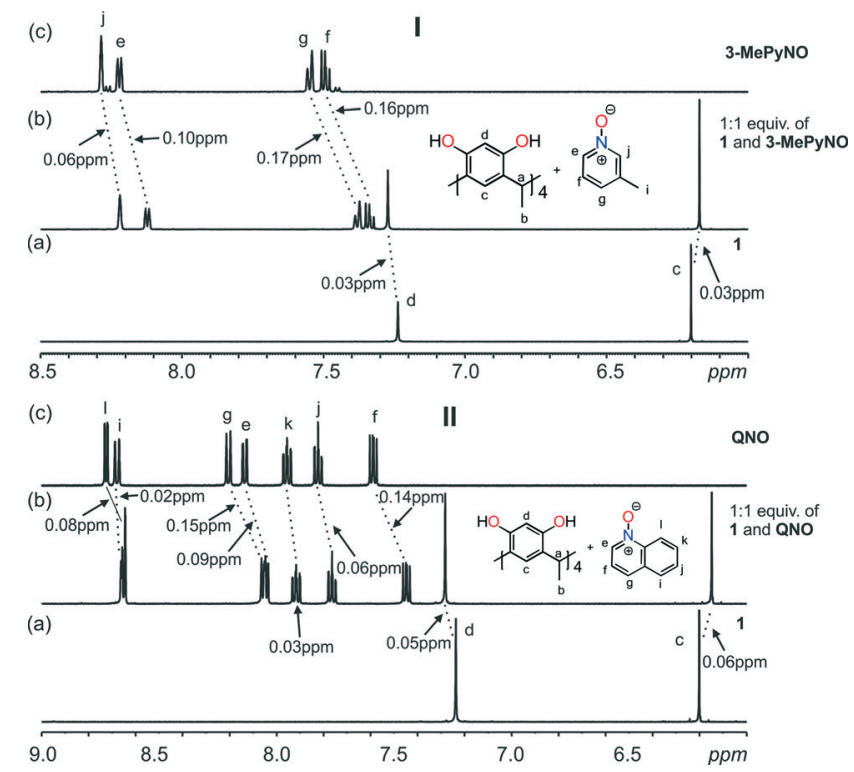

Fig. 6 Selected region of the ${ }^{1} \mathrm{H}$ NMR $\left(\mathrm{CD}_{3} \mathrm{OD}, 293 \mathrm{~K}\right)$ of: (I) a mixture of 3-MePyNO and 1, (a) 1 (6.6 mM), (b) 1+3-MePyNO (1:1), (c) 3MePyNO (6.6 mM) and (II) a mixture of QNO and 1, (a) 1 (6.6 mM), (b) $1+$ QNO (1:1), (c) QNO (6.6 mM). The shift changes in the guest and host signals of the complexes in ppm are highlighted.

\section{Conclusions}

The X-ray structures of seven PyNO complexes led to the conclusion that there is either endo complexation via $\mathrm{C}-\mathrm{H} \cdots \pi$ interactions or exo complexation via $(\mathrm{N}-\mathrm{O}) \cdots(\mathrm{H}-\mathrm{O})_{\text {host }}$ hydrogen bonds between the aromatic $\mathrm{N}$-oxides and $\mathrm{C}_{\text {methyl }}$-resorcinarene. Due

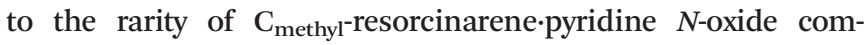
plexes, the endo host-guest complexes 2-MePyNO-1 and 3-MePyNO-1 were compared with our previous results with $\mathrm{C}_{\text {ethyl }}$-2-methylresorcinarene, ${ }^{21}$ which allowed us to probe factors such as the conformational flexibility of the cavity, the strength of $\mathrm{C}-\mathrm{H} \cdots \pi$ interactions and the localization of the guest molecule in the cavity. Despite the enhanced conformational flexibility, $\mathrm{C}_{\text {methyl-resorcinarene forms a pseudo- }}$ capsular 2:2 endo complex with 2-MePyNO and 3-MePyNO stabilized by $\mathrm{C}-\mathrm{H} \cdots \pi$ interactions in the solid state. The larger overall size of 3-MePyNO forces the $C_{4 v}$ crown conformation to open, very close to the ideal $C_{2 \mathrm{v}}$ boat conformation, but still having the guest inside the cavity. Additionally, the strong $\mathrm{C}-\mathrm{H} \cdots \pi$ interactions found in the endo complex 3-MePyNO-1 hint that the guest similar to 3-MePyNO with $\mathrm{C}_{\text {methyl }}$-resorcinarene could show interesting host-guest interactions. The larger guests 4-MePyNO, 2-MeNPyNO, 4-MeOPyNO, 4-PhPyNO and IsQNO do not form endo complexes, as the exo complexes are preferred due to the strong intermolecular hydrogen bonding between the host 1 molecules leading to 1-D chains. All exo complexes show very similar overall crystal packings. The complementary solution studies show that host-guest complexes between host 1 and all the $N$-oxide molecules, except 4-PhPyNO, are formed in solution. Furthermore, the variable temperature ${ }^{1} \mathrm{H}$ NMR 
measurements proved that the conformational changes in host 1 , observed in the solid state upon complexation, were not observed in solution.

\section{Acknowledgements}

The Academy of Finland (K. R.: grant no. 265328 and 263256; N. K. B.: grant no. 258653), the University of Jyväskylä and Aalto University are gratefully acknowledged for financial support.

\section{Notes and references}

1 J. W. Steed and P. A. Gale, Supramolecular Chemistry: From Molecules to Nanomaterials, 8 Volume Set, Wiley, 2012.

2 W. Sliwa and C. Kozlowski, Calixarenes and Resorcinarenes, Wiley, 2009.

3 M. He, R. J. Johnson, J. O. Escobedo, P. A. Beck, K. K. Kim, N. N. St. Luce, C. J. Davis, P. T. Lewis, F. R. Fronczek, B. J. Melancon, A. A. Mrse, W. D. Treleaven and R. M. Strongin, J. Am. Chem. Soc., 2002, 124, 5000-5009.

4 N. K. Beyeh and K. Rissanen, Tetrahedron Lett., 2009, 50, 7369-7373.

5 P. Timmerman, W. Verboom and D. N. Reinhoudt, Tetrahedron, 1996, 52, 2663-2704.

6 (a) J. L. Atwood and A. Szumna, J. Supramol. Chem., 2002, 2, 479-482; (b) N. K. Beyeh and K. Rissanen, Isr. J. Chem., 2011, 51, 769-780; (c) N. K. Beyeh, A. Valkonen and K. Rissanen, Supramol. Chem., 2009, 21, 142-148; (d) H. Mansikkamaki, M. Nissinen and K. Rissanen, CrystEngComm, 2005, 7, 519-526.

7 (a) N. K. Beyeh, D. P. Weimann, L. Kaufmann, C. A. Schalley and K. Rissanen, Chem. - Eur. J., 2012, 18, 5552-5557; (b) N. K. Beyeh, M. Göth, L. Kaufmann, C. A. Schalley and K. Rissanen, Eur. J. Org. Chem., 2014, 2014, 80-85.

8 (a) H. Mansikkamaki, C. A. Schalley, M. Nissinen and K. Rissanen, New J. Chem., 2005, 29, 116-127; (b) M. Luostarinen, A. Åhman, M. Nissinen and K. Rissanen, Supramol. Chem., 2004, 16, 505-512.

9 (a) N. K. Beyeh, M. Kogej, A. Åhman, K. Rissanen and C. A. Schalley, Angew. Chem., Int. Ed., 2006, 45, 5214-5218; (b) T. Gerkensmeier, W. Iwanek, C. Agena, R. Fröhlich, S. Kotila, C. Näther and J. Mattay, Eur. J. Org. Chem., 1999, 1999, 2257-2262; (c) L. R. MacGillivray and J. L. Atwood, Nature, 1997, 389, 469-472.

10 (a) H. Mansikkamäki, M. Nissinen and K. Rissanen, Angew. Chem., 2004, 116, 1263-1266; (b) H. Mansikkamäki, S. Busi, M. Nissinen, A. Åhman and K. Rissanen, Chem. - Eur. J., 2006, 12, 4289-4296.

11 (a) M. Nissinen, E. Wegelius, D. Falabu and K. Rissanen, CrystEngComm, 2000, 2, 151-153; (b) M. Nissinen and K. Rissanen, Supramol. Chem., 2003, 15, 581-590.
12 (a) B.-Q. Ma and P. Coppens, Cryst. Growth Des., 2004, 4, 1377-1385; (b) B.-Q. Ma, Y. Zhang and P. Coppens, Cryst. Growth Des., 2001, 1, 271-275; (c) L. R. MacGillivray, P. R. Diamente, J. L. Reid and J. A. Ripmeester, Chem. Commun., 2000, 359-360; (d) G. Ferguson, C. Glidewell, A. J. Lough, G. D. McManus and P. R. Meehan, J. Mater. Chem., 1998, 8, 2339-2345; (e) P. Thuéry, M. Nierlich, Z. Asfari, J. Vicens, O. Morikawa and H. Konishi, Supramol. Chem., 2001, 13, 521-527; $(f)$ C. L. Raston and G. W. V. Cave, Chem. - Eur. J., 2004, 10, 279-282; $(g)$ P. O. Brown, G. D. Enright and J. A. Ripmeester, CrystEngComm, 2006, 8, 381-383.

13 CSD version 5.36 (November 2014), ConQuest Version 1.17; Search performed date, 17.12.2015. The CSD search was defined and limited to core $\mathrm{C}_{\text {methyl }}$-resorcinarene as the host molecule.

14 (a) P. O. Brown, G. D. Enright and J. A. Ripmeester, J. Supramol. Chem., 2002, 2, 497-500; (b) T. Friščić and L. R. MacGillivray, J. Organomet. Chem., 2003, 666, 43-48; (c) B.-Q. Ma, Y. Zhang and P. Coppens, CrystEngComm, 2001, 3, 78-80; (d) B.-Q. Ma, Y. Zhang and P. Coppens, J. Organomet. Chem., 2003, 68, 9467-9472; (e) B.-Q. Ma, Y. Zhang and P. Coppens, Cryst. Growth Des., 2002, 2, 7-13; $(f)$ L. R. MacGillivray and J. L. Atwood, J. Am. Chem. Soc., 1997, 119, 6931-6932; $(g)$ L. R. MacGillivray, K. T. Holman and J. L. Atwood, J. Supramol. Chem., 2001, 1, 125-130; (h) L. R. MacGillivray, G. S. Papaefstathiou, J. L. Reid and J. A. Ripmeester, Cryst. Growth Des., 2001, 1, 373-375; (i) L. R. MacGillivray, J. L. Reid and J. A. Ripmeester, Chem. Commun., 2001, 1034-1035; ( $j$ ) A. Nakamura, T. Sato and R. Kuroda, CrystEngComm, 2003, 5, 318-325; (k) L. R. MacGillivray, J. L. Reid and J. A. Ripmeester, CrystEngComm, 1999, 1, 1-4; (l) J. Zhang, M. Gembicky, M. Messerschmidt and P. Coppens, Chem. Commun., 2007, 2399-2401; (m) Y. Zhang, C. D. Kim and P. Coppens, Chem. Commun., 2000, 2299-2300.

15 A. R. Katritzky, Handbook of heterocyclic chemistry, Pergamon Press, 1985; A. Albini, Heterocyclic N-oxides, Taylor \& Francis, 1991.

16 R. Puttreddy and P. J. Steel, CrystEngComm, 2014, 16, 556-560 (references therein).

17 R. Puttreddy, O. Jurcek, S. Bhowmik, T. Makela and K. Rissanen, Chem. Commun., 2016, 52, 2338-2341.

18 (a) G. Zheng, Y.-Y. Li, H.-D. Guo, S.-Y. Song and H.-J. Zhang, Chem. Commun., 2008, 4918-4920; (b) L. Adriaenssens and P. Ballester, Chem. Soc. Rev., 2013, 42, 3261-3277.

19 N. K. Beyeh, R. Puttreddy and K. Rissanen, RSC Adv., 2015, 5, 30222-30226.

20 C. Janiak, J. Chem. Soc., Dalton Trans., 2000, 3885-3896.

21 R. Puttreddy, N. K. Beyeh and K. Rissanen, CrystEngComm, 2016, 18, 793-799.

22 Y. Zhang and P. Coppens, Private Commun., 2007 (CSD Code - IFOVIJ). 